\title{
HISTOMORFOMETRIA DE ORGÃOS LINFOIDES E DESENVOLVIMENTO INTESTINAL DE PINTOS DE CORTE ORIGINADOS DE MATRIZES COM DIFERENTES IDADES E SUBMETIDOS AO ESTRESSE POR CALOR NA INCUBAÇÃO
}

\author{
MORPHOLOGIGAL MEASUREMENTS OF LYMPHOID TISSUES AND \\ INTESTINAL DEVELOPMENT OF CHICKS FROM DIFFERENT BREEDER \\ AGES AND HATCHED UNDER HEAT STRESS
}

\author{
Nadja Susana Mogyca Leandro ${ }^{1^{*}}$ \\ Natali Almeida Gomes ${ }^{2}$ \\ Marcos Barcellos Café ${ }^{1}$ \\ Fabyola Barros Carvalho ${ }^{1}$ \\ José Henrique Stringhini ${ }^{1}$ \\ Michele Laboissière ${ }^{1}$ \\ 1 Universidade Federal de Goiás, Goiânia, GO, Brasil \\ 2Universidade Estadual de Goiás, São Luiz dos Montes Belos, GO, Brasil \\ *Autora para correspondência - mogyca@ufg.br
}

\section{Resumo:}

Objetivou-se avaliar o efeito da idade da matriz e da variação da temperatura de incubação sobre a qualidade do pinto neonato. $\mathrm{O}$ delineamento foi inteiramente casualizado em esquema fatorial $3 \times 2$ (três idades $\mathrm{x}$ duas temperaturas de incubação). Foram incubados 720 ovos, provenientes de matrizes com diferentes idades (30, 42 ou 64 semanas). A temperatura da máquina de incubar para os grupos controle foi mantida constante $\left(37,5^{\circ} \mathrm{C}\right)$ e para os tratamentos com estresse por calor foi aplicada uma temperatura de $39,0^{\circ} \mathrm{C}$ por $6 \mathrm{~h}$ durante o período de 10 a 18 dias de incubação. Cinco pintos por tratamento foram sacrificados para coletas de órgãos e realizada a histomorfometria intestinal, de baço e bursa. Os dados foram submetidos a análise de variância e foi utilizado o teste de Tukey (5\%). A área dos folículos da bursa foi maior nos pintos oriundos de matrizes mais velhas quando os ovos foram incubados em temperatura ideal. A temperatura de $39,0^{\circ} \mathrm{C}$ estimulou o desenvolvimento intestinal. A variação na temperatura de incubação prejudicou a qualidade de pintos, sobretudo para pintos originados de matrizes jovens. Pintos oriundos de matrizes velhas apresentaram melhor resposta imune e desenvolvimento intestinal, independentemente da variação da temperatura de incubação.

Palavras-chave: baço; bursa de Fabricius; frangos; imunidade; mucosa intestinal.

\section{Abstract:}

This study was carried out to evaluate the effect of breeder age and hatching temperature variations 
on chick quality. The experiment was a completely randomized design in a $3 \times 2$ factorial arrangement (three breeder ages and two hatching temperatures). We used 720 eggs from three breeder ages $\left(30,42\right.$, or 64 weeks). The hatching temperature for control group was $37.5{ }^{\circ} \mathrm{C}$ during all the hatching period and for the elevated temperature group, it was $39.0^{\circ} \mathrm{C}$ during $6 \mathrm{~h}$ between 10 and 18 days of incubation. Five chicks per treatment were euthanized by cervical dislocation for bursal and spleen morphological measurements. The data were analyzed using ANOVA and the differences among means were compared by Tukey test (5\%). Chicks from older flock had larger follicular area of bursa de Fabricius when hatched under normal temperature. The higher hatching temperature induced intestinal development because chicks hatched under high temperature had bigger crypt depth. Changes in hatching machine temperature affected young flock chick quality. Chicks from older flocks had better immune response.

Keywords: broiler; bursal; hatching; intestine; spleen.

Recebido em: 02 abril 2015

Aceito em: 03 novembro de 2016

\section{Introdução}

$\mathrm{Na}$ avicultura moderna, a qualidade de pintos de um dia é fundamental e, portanto, incubatórios comerciais, além de buscar resultados de eclosão, também tem focado na qualidade dos pintos neonatos. Além dos aspectos físicos de qualidade, há também os aspectos microbiológico e imunológico. O pinto de qualidade deve ser livre de bactérias e fungos patogênicos, ter boa imunidade maternal ser capaz de responder imunologicamente aos desafios de campo após a queda da imunidade passiva, recebida durante o período embrionário.

Segundo $\operatorname{Tizard}^{(1)}$, a resposta imune depende da formação de células que atuarão na imunidade celular ou humoral. Os órgãos linfoides primários regulam o desenvolvimento dos linfócitos e os secundários possuem células que capturam e processam os antígenos. Nas aves, a maturação das células B ocorre na bursa de Fabricius e a maturação das células T, no timo. O baço é um órgão linfoide secundário e apresenta dois tipos de polpas: a vermelha que filtra o sangue e acumula hemácias e a branca rica em linfócitos.

Alguns pesquisadores avaliaram indiretamente a resposta imune das aves por meio de morfometria de órgãos linfoides. Van der Pol et al. ${ }^{(2)}$ estudaram o peso do baço e da bursa de Fabricius de pintos neonatos de matrizes com diferentes idades e observaram que pintos oriundos de matrizes mais velhas apresentaram maior peso de bursa de Fabricius.

Por outro lado, o intestino também é importante no desenvolvimento da ave, principalmente na fase inicial de criação. Segundo Gimenez et al. ${ }^{(3)}$, na primeira semana ocorre grande desenvolvimento do aparelho digestório da ave em adaptação ao meio extra-ovo e à dieta exógena, o que se relaciona à mucosa do intestino delgado, a qual responde pela digestão e absorção dos nutrientes. Portanto, a mucosa intestinal deve estar íntegra e em intensa renovação, para que haja eficiência digestiva na ave. 
Um dos fatores que podem afetar tanto a imunidade das aves quanto o desenvolvimento intestinal é a idade da matriz. Estudos comprovam que matrizes mais velhas depositam mais imunoglobulinas e nutrientes na gema. Com isso, os pintos eclodem com maior imunidade maternal ${ }^{(4)}$ e podem apresentar maior desenvolvimento corporal, refletido na mucosa intestinal ${ }^{(3)}$.

Além da idade da matriz, a temperatura de incubação também afeta o desenvolvimento e a qualidade do pinto. Lourens et al. ${ }^{(5)}$ verificaram que os pintos eram mais pesados, na fase embrionária, quando incubados em temperatura constante em comparação com aqueles incubados com variação da temperatura. Além do peso do pinto neonato, o peso relativo de órgãos também pode ser afetado pela temperatura de incubação. Leksrisompong et al. ${ }^{(6)}$ estudaram o efeito de altas temperaturas $\left(39,5^{\circ} \mathrm{C}\right)$ na fase final de incubação sobre o desenvolvimento do pinto e observaram que o aumento da temperatura prejudicou o desenvolvimento do coração, intestino delgado, proventrículo e moela.

A temperatura de incubação também afeta o desenvolvimento da mucosa intestinal e consequentemente, o desenvolvimento da ave. Barri et al. ${ }^{(7)}$ estudaram a superfície da membrana celular de pintos incubados em diferentes temperaturas e observaram que o aumento na temperatura de incubação $\left(39,6{ }^{\circ} \mathrm{C}\right)$ provocou diminuição da expressão de peptídeos transportadores de micronutrientes na membrana plasmática de pintos.

Este estudo foi realizado para avaliar o efeito da idade da matriz e da variação da temperatura de incubação no desenvolvimento intestinal e dos órgãos linfoides de pintos de corte recém-eclodidos.

\section{Material e Métodos}

O experimento foi realizado no setor de Avicultura da Escola de Veterinária e Zootecnia e foi aprovado pela Comissão de Ética no Uso de Animais da Universidade Federal de Goiás, protocolado sob o $\mathrm{n}^{\mathrm{o}}$. 032/12.

Foram incubados 720 ovos provenientes de matrizes com três idades diferentes (30, 42 ou 64 semanas de idade) criadas sob condições semelhantes (nutricionais, de manejo e ambiente). Os ovos foram coletados em uma mesma granja e transportados no mesmo dia. Foram armazenados por três dias, pesados e selecionados de acordo com o peso médio de cada tratamento (idade das matrizes), com $10 \%$ de desvio padrão.

Os ovos foram distribuídos em delineamento inteiramente casualizado em esquema fatorial 3 x 2 (três idades de matriz $\mathrm{x}$ duas temperaturas de incubação). Os ovos foram distribuídos em incubadoras automáticas de estágio único (total de seis incubadoras) Premium Ecológica ${ }^{\circledR}$, que foram mantidas a $37,8{ }^{\circ} \mathrm{C}$ e $60 \%$ de umidade relativa. A temperatura da incubadora no grupo controle foi de $37,5^{\circ} \mathrm{C}$ constante durante todo o período de incubação. Para os tratamentos com elevação da temperatura de incubação foi aplicada uma elevação cíclica de temperatura, sendo alterada para $39,0{ }^{\circ} \mathrm{C}$ por $6 \mathrm{~h}$ durante o período de 10 a 18 dias de incubação. Cada incubadora recebeu 360 ovos, sendo 120 de cada idade de matriz.

O período de eclosão foi acompanhado a partir de 449 horas de incubação em intervalos de seis horas até o total de 504 horas. A qualidade dos pintos foi avaliada em dois períodos (simulando 
duas retiradas da máquina de eclosão), com 485 e 504 horas de incubação.

Após o nascimento, cinco pintos por tratamento foram pesados e submetidos a eutanásia (deslocamento cervical) para coleta de material e confecção das lâminas histológicas. Para a análise histológica do intestino delgado foram colhidos segmentos de $1 \mathrm{~cm}$ do duodeno, jejuno e íleo, sem a abertura da borda mesentérica devido às suas dimensões não permitirem tal manuseio. Os segmentos foram fixados em formol $10 \%$ por 24 horas. Posteriormente, foram lavados em álcool $70 \%$ e, em seguida, submetidos à desidratação por tratamento com álcool em concentrações crescentes (70-100\%). As amostras foram diafanizadas em xilol e incluídas em parafina. Foram preparadas lâminas de cada segmento e os cortes, com sete micrômetros de espessura, foram corados com Hematoxilina e Eosina. O baço e a bursa foram também submetidos ao mesmo procedimento.

Após o processamento das lâminas, foram fotografados quatro campos de cada lâmina e foram realizadas 10 leituras por lâmina, totalizando 40 leituras por ave. Foi avaliada a histomorfometria do trato gastrintestinal (intestino delgado) e a área dos folículos da bursa de Fabricius. A porcentagem da área de polpa branca em relação a área de polpa vermelha do baço foi realizada a partir das medidas das áreas, considerando-se toda a área do baço (100\%).

Após o procedimento de coloração das lâminas preparadas, foram fotografados quatro campos em cada lâmina de segmento intestinal e foram realizadas 10 leituras por campo, totalizando 40 leituras por ave da altura e largura de vilos e profundidade de criptas e das áreas do folículo da Bursa (Figura-1A). Também foram feitas medições de cinco campos de $4 \mathrm{~cm}^{2}$ por fotografia das lâminas do baço (Figura- 1B), considerando-se a área de polpa branca e área de polpa vermelha, por meio do software ImageJ. As fotografias das lâminas foram realizadas utilizando-se um microscópio ótico Leica acoplado a um sistema analisador de imagens Axio Vision® (versão 3.0). A relação vilo:cripta foi obtida dividindo-se a altura dos vilos pela profundidade das criptas.
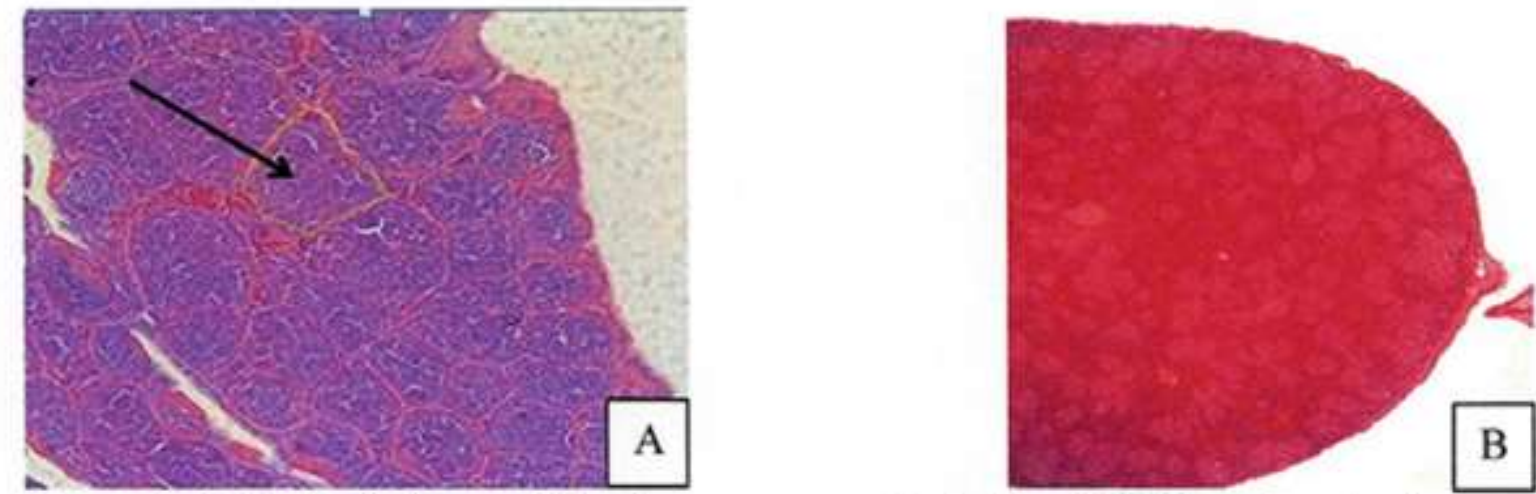

Figura 1. Folículo de bursa utilizado na mensuração de área (A); área de polpa branca e área de polpa vermelha de baço (B)

As variáveis quantitativas foram analisadas pela ANOVA, com auxílio do programa computacional $\mathrm{SAS}^{(8)} \mathrm{e}$, quando necessário, as médias foram comparadas pelo teste Tukey $(\mathrm{P}<0,05)$. 


\section{Resultados e Discussão}

Houve interação $(\mathrm{P}<0,05)$ entre os fatores (temperatura de incubação e idade das matrizes) sobre a porcentagem da área branca do baço e a área do folículo da bursa (Tabela 1) e matrizes mais novas produziram pintos neonatos com maior porcentagem da área branca quando os ovos foram mantidos em temperatura ideal de incubação (Tabela 2).

A polpa branca do baço favorece a resposta imune, pois é rica em linfócitos ${ }^{(1)}$ e, assim, pôde-se inferir que pintos oriundos de matrizes jovens apresentavam melhor imunidade quando incubados em temperatura constante, já que a oscilação para temperatura mais elevada $\left(39{ }^{\circ} \mathrm{C}\right)$ prejudicou o desenvolvimento desse órgão. Matrizes de idade intermediária apresentaram pintos com pior imunidade, independente do estresse por alta temperatura $(\mathrm{P}<0,05)$.

Já os embriões oriundos de matrizes com 42 e 64 semanas de idade foram mais resistentes a variações de temperatura, pois o aumento da temperatura para $39{ }^{\circ} \mathrm{C}$ não foi prejudicial para o desenvolvimento do baço. Como as matrizes mais velhas produzem ovos maiores, é possível que nesses ovos o estresse não tenha sido suficiente para provocar danos, ou pode não ter havido aquecimento suficiente no interior dos ovos, já que a temperatura controlada foi a da incubadora e não a temperatura dos ovos. Assim, máquinas com problemas de oscilação na temperatura podem prejudicar principalmente a resposta imune de pintos oriundos de matrizes mais jovens.

Tabela 1. Efeito da idade das matrizes e do aumento da temperatura durante a incubação sobre a porcentagem da polpa branca do baço e da área dos Folículos da Bursa $\left(\mu \mathrm{m}^{2}\right)$

\begin{tabular}{lcc}
\hline & \multicolumn{2}{c}{ Variáveis estudadas } \\
\hline Fatores & $\begin{array}{c}\text { Polpa branca } \\
\text { do Baço }(\%)\end{array}$ & $\begin{array}{c}\text { Área dos Folículos } \\
\text { Bursa }\left(\boldsymbol{\mu m ^ { 2 }}\right)\end{array}$ \\
\hline Idades da matriz & \multicolumn{3}{c}{ Valor de P } \\
Temperatura de incubação & $<0,0001$ & 0,055 \\
Idade*temperatura $^{1}$ & 0,007 & 0,429 \\
$\mathrm{CV}(\%)$ & 0,030 & 0,016 \\
\hline
\end{tabular}

${ }^{1} 39,0^{\circ} \mathrm{C}$ por $6 \mathrm{~h}$ (durante o período de 10 a 18 dias de incubação)

A área dos folículos (Tabela 2) foi maior $(\mathrm{P}<0,05)$ nas aves oriundas de matrizes mais velhas $(64$ semanas) em relação às mais novas (30 semanas), quando os ovos foram incubados em temperatura ideal.

Os resultados obtidos neste estudo estão de acordo com os observados por Van der Pol et al. ${ }^{(2)}$, que verificaram que, em temperatura constante de incubação, houve aumento do peso da bursa de Fabricius em pintos oriundos de matrizes mais velhas, embora os autores não tenham avaliado área de folículo da bursa. Esses resultados também corroboram os observados por Leandro et al. ${ }^{(9)}$ que, em estudo com pintos originados de matrizes com diferentes idades, mas em condições ideais de 
temperatura, observaram que matrizes mais velhas originaram pintos com melhor resposta imune.

Os folículos da bursa são massas arredondadas de células do sistema imune, como linfócitos, plasmócitos e macrófagos. Na bursa, ocorrem a maturação e a diferenciação das células produtoras de anticorpos, os linfócitos B, e quando o processo de maturação é finalizado, as células B restantes se deslocam para os órgãos linfoides secundários ${ }^{(1)}$. Como a idade da matriz pode interferir no desenvolvimento dos órgãos do sistema imune do pinto, pode-se inferir que pintos de matrizes mais velhas podem apresentar melhor resposta imune do que a de pintos de matrizes jovens. Além disso, Ulmer-Franco et al. ${ }^{(4)}$ observaram maior capacidade de transferência de imunoglobulinas para embrião/pintinho em matrizes mais velhas em relação às mais novas.

Tabela 2. Desdobramento da interação entre idade da matriz e temperatura de incubação na porcentagem de polpa branca de baço e na área do folículo da Bursa em pintos oriundos de matrizes de diferentes idades e submetidos à variação da temperatura de incubação

\begin{tabular}{lllc}
\hline \multicolumn{4}{c}{ Polpa branca do baço (\%) } \\
\hline \multicolumn{4}{c}{ Idade das matrizes (semanas) } \\
Temp.de incubação $\left({ }^{\circ} \mathrm{C}\right)$ & 30 & 42 & 64 \\
\hline 37,5 & $68,0 \mathrm{Aa}$ & $45,6 \mathrm{Ca}$ & $51,5 \mathrm{Ba}$ \\
$39,0^{1}$ & $53,6 \mathrm{Ab}$ & $45,1 \mathrm{Ba}$ & $50,1 \mathrm{Aa}$ \\
\hline
\end{tabular}

\begin{tabular}{lclc}
\hline \multicolumn{4}{c}{ Área do Folículo da Bursa $\left(\mu \mathrm{m}^{2}\right)$} \\
\hline \multicolumn{4}{c}{ Idade das matrizes (semanas) } \\
Temp.de incubação $\left({ }^{\circ} \mathrm{C}\right)$ & 30 & 42 & 64 \\
\hline 37,5 & $598,96 \mathrm{Ba}$ & $629,32 \mathrm{ABa}$ & $676,19 \mathrm{Aa}$ \\
$39,0^{1}$ & $675,47 \mathrm{Aa}$ & $581,31 \mathrm{Aa}$ & $614,61 \mathrm{Aa}$ \\
\hline
\end{tabular}

Médias seguidas por letras maiúsculas (linhas) e minúsculas (colunas) diferem entre si pelo teste Tukey $(\mathrm{P}<0,05) \cdot{ }^{1} 39,0^{\circ} \mathrm{C}$ por $6 \mathrm{~h}$ (durante o período de 10 a 18 dias de incubação).

É possível que embriões de matrizes mais velhas sejam mais resistentes a variações de temperatura durante a incubação, podendo ser incubados em máquina de estágio múltiplo, e os ovos de matrizes jovens sejam incubados em máquinas de estágio único, pois os embriões desse tipo de matriz são mais sensíveis a variações de temperatura no período embrionário ${ }^{(6)}$. Oznurlu et al. ${ }^{(10)}$, ao estudarem a influência da temperatura de incubação (medida na casca do ovo) sobre o sistema imunológico, ressaltaram que o desenvolvimento da bursa e timo foi reduzido pelas temperaturas elevadas ( 37,8 ${ }^{\circ} \mathrm{C}, 38,8^{\circ} \mathrm{C}, 40,1{ }^{\circ} \mathrm{C}$ e $40,6{ }^{\circ} \mathrm{C}$ ) e concluíram que a temperatura elevada na incubação pode resultar em baixa imunidade nos lotes de frango de corte.

Quanto aos resultados da histomorfometria intestinal (Tabela 3) de pintos oriundos de matriz com diferentes idades e sob variação da temperatura de incubação, notou-se efeito da interação para comprimento de vilo $(\mathrm{P}<0,05)$ e profundidade de criptas (considerando o $\mathrm{P}=0,0582)$ do duodeno. Houve interação $(\mathrm{P}<0,05)$ para o comprimento de vilo e profundidade de cripta do íleo.

No desdobramento da interação entre os grupos idade de matriz e temperatura de incubação, para altura de vilo $(\mathrm{P}=0,0011)$ e profundidade de criptas $(\mathrm{P}=0,0582)$ do duodeno, observou-se que matrizes mais velhas resultaram em pintos neonatos com maior desenvolvimento intestinal, em 
condições de temperatura ideal de incubação $\left(37,5^{\circ} \mathrm{C}\right)$. No entanto, em pintos oriundos de matrizes jovens houve um maior estímulo do desenvolvimento intestinal quando os embriões foram submetidos ao aumento da temperatura de incubação $\left(39,0{ }^{\circ} \mathrm{C}\right)$ e esse fato pode ser observado principalmente a partir do resultado da altura do vilo do duodeno.

Considerando-se a temperatura ideal de incubação, resultados semelhantes foram encontrados por Maiorka et al. ${ }^{(11)}$ e Agostinho et al. ${ }^{(12)}$, que verificaram que pintos originados de matrizes jovens (30 e 33 semanas), em condições normais de incubação, apresentavam menor desenvolvimento intestinal do que matrizes mais velhas (60 e 68 semanas).

Tabela 3. Histomorfometria intestinal de pintos oriundos de matrizes de diferentes idades e submetidos a diferentes temperaturas de incubação

\begin{tabular}{|c|c|c|c|c|c|c|}
\hline & $\begin{array}{l}\text { Duodeno } \\
(\mu \mathrm{m})\end{array}$ & & $\begin{array}{l}\text { Jejuno } \\
(\mu \mathrm{m})\end{array}$ & & $\begin{array}{l}\text { f́leo } \\
(\mu \mathrm{m})\end{array}$ & \\
\hline $\begin{array}{l}\text { Idade } \\
\text { (semanas) }\end{array}$ & Vilo & Cripta & Vilo & Cripta & Vilo & Cripta \\
\hline 30 & 302,4 & 50,4 & $208,6 \mathrm{c}$ & $53,4 \mathrm{c}$ & 229,7 & 61,84 \\
\hline 42 & 465,2 & 75,1 & $231,9 b$ & $58,0 \mathrm{~b}$ & 268,1 & 73,43 \\
\hline 64 & 455,7 & 70,1 & $262,6 \mathrm{a}$ & $64,2 \mathrm{a}$ & 263,5 & 70,38 \\
\hline \multicolumn{7}{|l|}{ Temp. } \\
\hline $37,5\left(^{\circ} \mathrm{C}\right)$ & 364,0 & 59,0 & 240,1 & $56,0 \mathrm{~b}$ & 238,4 & 66,08 \\
\hline $39,0^{1}\left({ }^{\circ} \mathrm{C}\right)$ & 453,6 & 71,4 & 235,7 & $62,4 a$ & 262,8 & 69,67 \\
\hline Grupos & \multicolumn{6}{|c|}{ Valor de P } \\
\hline Idades & $<0,0001$ & $<0,0001$ & $<0,0001$ & $<0,0001$ & 0,010 & $<0,0001$ \\
\hline Temp. & $<0,0001$ & 0,0042 & 0,768 & 0,0004 & 0,0028 & 0,0689 \\
\hline Idade*temp & 0,0011 & 0,0582 & 0,274 & 0,686 & 0,002 & $<0,0001$ \\
\hline $\mathrm{CV}(\%)$ & 23,4 & 26,8 & 24,8 & 26,6 & 25,51 & 33,0 \\
\hline
\end{tabular}

Médias seguidas de letras diferentes nas colunas diferem entre si pelo teste Tukey $(\mathrm{P}<0,05)$.

${ }^{1} 39,0^{\circ} \mathrm{C}$ por $6 \mathrm{~h}$ durante o periodo de 10 a 18 dias de incubação.

Com relação ao efeito do aumento da temperatura durante a incubação, os dados encontrados neste estudo discordam dos obtidos por Leiksrisompong et al. ${ }^{(6)}$, que observaram que o peso do intestino delgado de pintos neonatos submetidos a altas temperaturas $\left(39,9^{\circ} \mathrm{C}\right)$, durante o período final de incubação, foram menores do que os daqueles incubados em temperatura normal $\left(38{ }^{\circ} \mathrm{C}\right)$. A diferença de resultados entre o presente estudo e os autores citados pode ser devido à diferença de temperaturas empregadas nos experimentos, pois estudos mostraram que variações de $1^{\circ} \mathrm{C}$ podem modificar o metabolismo embrionário de pintos $^{(13)}$.

Variações de temperatura podem afetar a velocidade de desenvolvimento de órgãos, podendo ou não afetar a eclodibilidade, e podem afetar o crescimento proporcional e/ou os processos funcionais do embrião ${ }^{(14)}$. Nesta pesquisa, o estímulo ao desenvolvimento de órgãos linfoides e intestino delgado provocado pela oscilação da temperatura de incubação para $39^{\circ} \mathrm{C}$ não pode ser considerado como positivo, sendo necessários mais estudos nesse sentido. Entretanto, Yalçin et al. ${ }^{(15)}$ testaram o 
aumento da temperatura de incubação para $38,5^{\circ} \mathrm{C}$ durante 6 horas/dia, do $10^{\circ}$ ao $18^{\circ}$ dia de incubação, e verificaram um crescimento acelerado em relação ao grupo controle, com maior peso do pinto neonato. Do mesmo modo, Tzschentke e Halle ${ }^{(16)}$, estudando o desempenho de frangos de corte submetidos ao curto período de estresse térmico durante a fase embrionária (temperatura de incubação aumentada para $38,4{ }^{\circ} \mathrm{C}$, durante duas horas/dia), verificaram que o aumento da temperatura durante a incubação proporcionou melhor desempenho do frango, tanto para o ganho de peso como para a conversão alimentar.

Para o comprimento dos vilos $(\mu \mathrm{m})$ e profundidade das criptas do íleo de pintos neonatos, pôde-se observar que houve interação $(\mathrm{P}<0,05)$ entre idade de matrizes e temperatura de incubação. Os resultados mostraram que, em condições adequadas de temperatura, a idade das matrizes influenciou o comprimento de vilos dos pintos neonatos, sendo que os pintos oriundos de matrizes de idade intermediária (42 semanas) apresentaram menor altura de vilos. Em condições de temperatura oscilando para $39^{\circ} \mathrm{C}$, o menor resultado foi observado em matrizes jovens $(\mathrm{P}<0,05)$. Não houve efeito $(\mathrm{P}>0,05)$ da oscilação da temperatura da máquina de incubar no desenvolvimento dos vilos do íleo em pintos oriundos de matrizes de 64 semanas de idade.

Para a profundidade de cripta do íleo, pôde-se observar que aves provenientes de matrizes com idade intermediária apresentaram melhor desenvolvimento de criptas; entretanto, quando houve oscilação da temperatura de incubação, os melhores resultados foram obtidos nas aves oriundas de matrizes de mais idade (60 semanas).

Para o jejuno (Tabela 3) não houve interação entre os grupos estudados, sendo que houve efeito da idade da matriz sobre altura de vilo e profundidade de cripta $(\mathrm{p}<0,05)$. Verificou-se maior desenvolvimento intestinal para pintos oriundos de matrizes mais velhas. $\mathrm{O}$ aumento da altura de vilo e profundidade de cripta de acordo com a idade das matrizes está em consonância com os resultados encontrados por Gimenez et al. ${ }^{(3)}$, que verificaram melhor área de digestão e de absorção intestinal dos embriões e neonatos oriundos de matrizes mais velhas.

O desenvolvimento de todos os tecidos pode ser afetado pelas condições de temperatura, durante a incubação $^{(17)}$ e, como demonstrado neste estudo, a oscilação da temperatura afetou os diferentes órgãos avaliados e foi dependente da idade da matriz. De acordo com a literatura, outros fatores também podem afetar a resposta fisiológica do embrião, como período de incubação no qual haverá uma oscilação da temperatura, da própria temperatura, do tempo de aplicação da elevação da temperatura, da linhagem e de qual tecido está sendo avaliado. Esses efeitos podem ser positivos ou negativos em relação ao desempenho e mortalidade durante a fase de criação ${ }^{(13,14,17-21)}$. 
Tabela 4. Desdobramento da interação entre idade de matrizes e temperatura de incubação sobre comprimento de vilos $(\mu \mathrm{m})$ e profundidade de criptas $(\mu \mathrm{m})$ de duodeno e do ileo de pintos neonatos

\begin{tabular}{|c|c|c|c|}
\hline \multicolumn{4}{|c|}{ Duodeno } \\
\hline \multicolumn{4}{|c|}{ Altura de vilos $(\mu \mathrm{m})$} \\
\hline & \multicolumn{3}{|c|}{ Idade das matrizes (semanas) } \\
\hline Temperatura $\left({ }^{\circ} \mathrm{C}\right)$ & 30 & 42 & 64 \\
\hline 37,5 & $264,66 \mathrm{Bb}$ & $442,76 \mathrm{Aa}$ & $453,16 \mathrm{Aa}$ \\
\hline $39,0^{1}$ & $401,25 \mathrm{Ba}$ & $484,28 \mathrm{Aa}$ & $458,79 \mathrm{Aa}$ \\
\hline \multicolumn{4}{|c|}{ Profundidade de criptas $(\mu \mathrm{m})$} \\
\hline Temperatura $\left({ }^{\circ} \mathrm{C}\right)$ & 30 & 42 & 64 \\
\hline 37,5 & $45,53 \mathrm{Bb}$ & $74,00 \mathrm{Aa}$ & $68,13 \mathrm{Aa}$ \\
\hline $39,0^{1}$ & $62,86 \mathrm{Ba}$ & $76,17 \mathrm{Aa}$ & $72,48 \mathrm{Aba}$ \\
\hline \multicolumn{4}{|c|}{ Íleo } \\
\hline \multicolumn{4}{|c|}{ Altura de vilos $(\mu \mathrm{m})$} \\
\hline \multicolumn{4}{|c|}{ Idade das matrizes (semanas) } \\
\hline Temperatura $\left({ }^{\circ} \mathrm{C}\right)$ & 30 & 42 & 64 \\
\hline 37,5 & $236,18 \mathrm{Aa}$ & $196,40 \mathrm{Bb}$ & $251,01 \mathrm{Aa}$ \\
\hline $39,0^{1}$ & $223,52 \mathrm{Ba}$ & $284,69 \mathrm{Aa}$ & $271,69 \mathrm{Aa}$ \\
\hline \multicolumn{4}{|c|}{ Profundidade de criptas $(\mu \mathrm{m})$} \\
\hline Temperatura $\left({ }^{\circ} \mathrm{C}\right)$ & 30 & 42 & 64 \\
\hline 37,5 & $58,07 \mathrm{Ba}$ & $104,95 \mathrm{Aa}$ & $63,71 \mathrm{Bb}$ \\
\hline 39,0 & $65,50 \mathrm{Ba}$ & $66,15 \mathrm{Bb}$ & $74,75 \mathrm{Aa}$ \\
\hline
\end{tabular}

Médias seguidas por letras maiúsculas (linhas) e minúsculas (colunas) diferem entre si pelo teste Tukey $(\mathrm{P}<0,05) \cdot{ }^{1} 39,0^{\circ} \mathrm{C}$ por $6 \mathrm{~h}$ durante o periodo de 10 a 18 dias de incubação.

\section{Conclusões}

A variação na temperatura da máquina de incubação $\left(39^{\circ} \mathrm{C}\right)$ prejudica o desenvolvimento de pintos neonatos, principalmente aqueles oriundos de matrizes jovens. Pintos oriundos de matrizes de 64 semanas apresentam maior desenvolvimento intestinal e de órgãos linfoide. A oscilação da temperatura acima do recomendado na incubação $\left(39^{\circ} \mathrm{C}\right)$ acelera o desenvolvimento intestinal de pintos.

\section{Referências}

1. Tizard IR. Imunologia Veterinária. $8^{\mathrm{a} E d}$. Rio de Janeiro: Elsevier, 2008. 587p. Português.

2. Van Der Pol CW, Van Roovert-Reijrink IAM, Maatjens CM, Van Den Brand H, Molenaar, R. Effect of 
relative humidity during incubation at a set eggshell temperature and brooding temperature posthatch on embryonic mortality and chick quality. Poultry cience. 2013; 92(8) 2145-2155.

3. Gimenez AC, Riccardi RR, Malheiros EB, Boleli IC. Influência do sexo e do peso dos ovos sobre a altura dos vilos e profundidade de criptas do intestino delgado de embriões de pintos de corte. Ciência Animal Brasileira. 2008; 9(3):608-616. Português

4. Ulmer-franco AM, Cherian G, Quezada N, Fasenko GM, McMullen LM. Hatching egg and newly hatched chick yolk sac total IgY content at three broiler breeder flock ages. Poultry Science. 2012; 91 (3):758-764.

5. Lourens A, Van Den Brand H, Meijerhof R, Kemp B. Effect of eggshell temperature during incubation on embryo development, hatchability and posthatch development. Poultry Science. 2005; 84(6):914-920.

6. Leksrisompong N, Romero-Sanchez H, Plumstead PW, Brannan KE, Brake J. Broiler incubation. 1. Effected temperature during late incubation on body weight and organs of chicks. Poultry Science. 2007; 86(12):2685-2691.

7. Barri A, Honaker CF, Sottosanti JR, Hulet RM, Mcelroy AP. Effect of incubation temperature on nutrient transporters and small intestine morphology of broiler chickens. Poultry Science. 2011; 90 (1):118-125.

8. SAS Institute. Statistical Analysis System: user guide [CD-ROM]. Version 8. Cary (NC): SAS Insitute Inc., 2002.

9. Leandro NM, Ali R, Koci M, Moraes M, Eusebio-Balcazar PE, Jornigan J., Malheiros RD, Wineland, MJ, Brake J, Oviedo-Rondón EO. Maternal antibody transfer to broiler progeny varies among strains and is affected by grain source and cage density. Poultry Science. 2011; 90(12):2730-2739.

10. Oznurlu Y, Celik I, Telatar T, Sur E. Histochemical and histological evaluations of the effects of high incubation temperature on embryonic development of thymus and bursa of Fabricius in broiler chickens. British Poultry Science. 2010; 51(1):43-51.

11. Maiorka A, Santin E, Fischer Da Silva, AV, Bruno, LDG, Bolell, IC, Macari, M. Desenvolvimento do Trato Gastrointestinal de Embriões Oriundos de Matrizes Pesadas de 30 e 60 Semanas de Idade. Revista Brasileira de Ciências Avícolas. 2000; 2(2):141-148. Português.

12. Agostinho, TSP, Calixto, LFL, Gomes, AVCG, Togashi, CK, Curvello, FA, Lima, MF. Desenvolvimento de órgãos do trato gastrintestinal e desempenho de frangos de corte arraçoados na fase pré- alojamento. Revista Brasileira. Saúde Produção Animal. 2012; 13(4): 1143-1155. Português.

13. Lourens A, Van Den Brand H, Heetkamp MJW, Meijerhof R, Kemp B. Effects of eggshell temperature and oxygen concentration on embryo growth and metabolism during incubation. Poultry Science. 2007; 86 (10):2194-2199

14. Decuypere E, Michels H. Incubation temperature as a management tool: a review. World's Poultry Science Journal. 1992; 48(1):28-38.

15. Yalçin S, Abuk MC, Bruggeman V, Babacanog E, Buyse J, Decuypere E, Siegel PB. Acclimation to heat stress during incubation: 1. Effects on embryonic morphological traits, blood biochemistry, and hatching performance. Poultry Science. 2008; 87(6):1219-1228.

16. Tzschentke B, Halle I. Influence of temperature stimulation during the last 4 days of incubation on secondary sex ratio and later performance in male and female broiler chicks. British Poultry Science. 2009; 50 (5):634-640.

17. Aksit M, Yalçin S, Yenisey Ç, Özdemir D. Brooding temperatures for chicks acclimated to heat during incubation: effects on post-hatch intestinal development and body weight under heat stress. British Poultry Science. 2010; 51(3): 444-452. 
18. Moraes VMB, Malheiros RD, Bruggeman V, Colli A, Tona K, Van As P, Onagbesan OM, Buyse J, Decuypere E, Macari M. Effect of thermal conditioning during incubation embryo development on aspects of physiological responses of broilers to heat stress.Journal of Thermal Biology.2003; 28(2):133-140.

19. Molenaar R, Hulet R, Meijerhof R, Maatjens CM, Kemp B, Van den Brand H. High eggshell temperatures during incubation decrease growth performance and increase the incidence of ascites in broiler chickens. Poultry Science. 2011; 90(3):624-632.

20. Oviedo-Rondon EO, Wineland MJ, Cutchin H, McElroy A, Barri A, Martin S. Effect of incubation temperatures and chick transportation conditions on bone development and leg health. Journal of Applied Poultry Research. 2009; 18(4):671-678.

21. Flores F, Nääs IA, Garcia RG. Variação térmica durante a incubação de ovos e seus efeitos sobre os componentes imunológicos do embrião. Enciclopédia Biosfera, Centro Científico Conhecer. 2013; 9(17):2594-2612. Português. 